\title{
Mente/mente humana \\ Virtual/atual
}

\author{
Maria Ogécia Drigo ${ }^{1}$ \\ Universidade de Sorocaba
}

Resumo: Com o propósito de explicar a mente humana como uma atualização da mente, segundo as idéias de Charles Sanders Peirce, relata-se, inicialmente, resultados de uma pesquisa teórica empreendida para comprovar que a semiose, na mente humana, se constitui como um processo auto-organizativo e, em seguida, trata-se do par virtual/atual e a sua relação com a terceiridade, uma das categorias da fenomenologia peirceana.

Palavras-chave: virtual; mente humana; semiose

Abstract: The purpose here is to explain the human mind as updating of the mind, according to Peirce' ideas. We relate, firstly, results of a theoretical research developed to demonstrate that the semiosis, in the human mind, is constituted as a self-organization process; then, we will treat the pair virtual/updating and its relation with the Thirdness, one of the categories in Peirce's phenomenology.

Keywords: virtual; human mind; semiosis.

\footnotetext{
${ }^{1}$ Professora na Universidade de Sorocaba (Uniso); Doutora em Comunicação e Semiótica pela PUC/SP. Membro do Centro de Estudos Peirceanos - PUC/SP . Projeto de pesquisa em desenvolvimento: "A didática que se delineia na relação signo/significação, à luz das idéias peirceanas.” Agência de fomento: CNPq.
} 


\section{Introdução}

Sem pretender dirimir questionamentos que envolvem a mente humana constata-se que predomina a tendência de estudá-la alocada no corpo e, portanto, envolvendo processos físico/químicos. Há diferentes modos de explicar a existência da mente humana.

$\mathrm{Na}$ abordagem dualista se admite que a mente humana é algo não-físico, logo, ela não se constitui em um objeto de estudo de ciências como a física, a neurobiologia e a ciência da computação. O dualismo não é a concepção mais defendida na comunidade científica, mas é a idéia comum em meio às pessoas em geral; está arraigada na maioria das religiões populares e é a teoria da mente que predomina no ocidente, segundo Churchland (2004, p. 26).

Descartes (1596-1650) postulou a existência de dois tipos de substâncias. O espírito humano, "enquanto é uma coisa pensante e não extensa, em comprimento, largura e profundidade, e que não participa de nada que pertence ao corpo, é incomparavelmente mais distinta do que a idéia de qualquer coisa corporal.”(DESCARTES, 1975, p. 123)

Há também o dualismo de propriedade, no qual se postula a existência de uma matéria, a do cérebro, dotada de um conjunto especial de propriedades das quais nenhum outro tipo de objeto físico dispõe, propriedades consideradas nãofísicas.

O dualismo postula dois tipos de matéria e/ou duas classes de propriedades, enquanto o materialismo postula apenas um tipo de substância (a matéria física) e uma classe de propriedades, as físicas.

Para Churchland (2004, p. 44-5), a neurologia explica, em parte, a constituição do cérebro, as leis físicas que o governam, bem como comportamentos do ser humano, em termos das propriedades elétricas, químicas e físicas do cérebro.

Se existisse uma entidade distinta, na qual o raciocínio, a emoção e a consciência têm lugar, e se essa entidade dependesse do cérebro unicamente para as experiências sensoriais, como entrada de dados e para execuções da vontade, como saída, então seria razoável que a razão, a emoção e a consciência não sofressem 
prejuízo quando cérebro sofre danos. No entanto, não é o que ocorre. Assim, o materialismo se fortalece. Mas há diversas formas de materialismo: o behaviorismo filosófico, o materialismo reducionista, o funcionalismo e o materialismo eliminacionista.

Para Churchland (ibid, p. 48-78), o behaviorismo filosófico não é uma teoria sobre o que são os estados mentais (em sua natureza interior), mas supõe que explicar emoção, sensação, crença e desejo é o mesmo que explicar padrões de comportamento, potenciais ou reais. No materialismo reducionista, ou teoria da identidade, os estados mentais são considerados estados físicos do cérebro e a cada tipo de estado ou processo mental é numericamente idêntico a (é uma e mesma coisa que) algum tipo de estado ou processo mental no interior do cérebro ou no sistema nervoso central. No funcionalismo, todo tipo de estado mental é um conjunto de relações causais que ele mantém com os efeitos do meio ambiente sobre o corpo, com outros estados mentais ou com o comportamento corporal. Assim, no behaviorismo os estados mentais seriam determinados em termos de entradas de dados do meio ambiente e saídas comportamentais. Para o funcionalista isso não é possível, pois a caracterização adequada de quase todos os estados mentais envolve uma referência não-eliminável a uma série de estados mentais com o qual o estado mental em questão está conectado em termos causais. Para o materialista eliminacionista as correspondências um-a-um, propostas no materialismo reducionista, não existem e, por outro lado, a estrutura psicológica do senso comum é uma concepção falsa e radicalmente enganosa das causas do comportamento humano e da natureza da atividade cognitiva.

Sendo anti-cartesiano ao rejeitar o dualismo da matéria, Peirce diz que:

a velha noção dualística de mente e matéria, tão proeminente no cartesianismo, como dois tipos de substâncias radicalmente diferentes, dificilmente hoje irá encontrar defensores. Rejeitando-a, somos levados a alguma forma de hilozoísmo, e o caso contrário denominado monismo. Surge, então, a questão se, de um lado, a lei física e, de outro, a lei psíquica devem ser consideradas:

a)como independentes, constituindo uma doutrina freqüentemente chamado monismo, mas que eu denomino neutralismo; ou

b)a lei psíquica como a derivada e especial, e apenas a lei física como primordial, o que é materialismo; ou 
c)a lei física como derivada e especial, e somente a lei psíquica como primordial, o que é idealismo. (CP 6.24).

"A única teoria inteligível do universo é a do idealismo objetivo, na qual matéria é mente esgotada, hábitos inveterados se tornam leis físicas.”(CP 6.25). Logo, “o sinequista não admitirá que os fenômenos físicos e psíquicos sejam inteiramente distintos - como se fossem categorias diferentes de substâncias ou lados separados de um anteparo."(CP 7.570).

A matéria, orgânica ou não, é um tipo de mente, de pensamento. Ele se faz presente também "no trabalho das abelhas, dos cristais e por todo o mundo puramente físico e não há como negar que ele está ali, bem como não dá para negar as cores, formas etc. dos objetos que ali estão. Não só o pensamento está no mundo orgânico, como ele ali, também se desenvolve.”(CP 4.551).

Assim há leis que se atualizam nessas instâncias físicas e elas diferem apenas em grau. Por exemplo, no trabalho das abelhas a ação dos signos é mais previsível que na mente humana. Como pressuposto para a compreensão da atualização da mente, no ser humano, como um processo auto-organizativo faz-se necessário admitir que não há dicotomia entre mente e matéria e que a lei física é derivada e especial, sendo a lei psíquica, a primordial.

Mas o percurso que alcançou os processos auto-organizativos passou pela ciência cognitiva. As teorias sobre estruturas dissipativas (processos autoorganizativos) de Ilya Prigogine - que se considerou mais adequada-, vão ao encontro das investigações empreendidas por Peirce com o protoplasma. Prigogine (1996, p. 71), valendo-se de uma metáfora, afirma que "pode-se dizer que no equilíbrio a matéria é cega, ao passo que longe do equilíbrio ela começa a ver", o que nos remete à questão da continuidade entre mente e matéria, o sinequismo peirceano. A seguir, de modo resumido, abordam-se algumas idéias de Ilya Prigogine sobre estruturas dissipativas e idéias peirceanas.

\section{Sobre estruturas dissipativas e idéias peirceanas}

Resultados de investigações de Peirce (CP 6.278 - 283) mostram que ele abordou o aspecto material do raciocínio e o vinculou às substâncias químicas do protoplasma e ao sistema nervoso. As suas investigações tomavam como 
fundamentação os conhecimentos do final do século XIX (1879). Ele explicou as três propriedades fundamentais do protoplasma: sensibilidade, movimento e crescimento e as vinculou as três funções do sistema nervoso: excitação da célula, transferência pelas fibras e fixação da tendência definitiva sob a influência do hábito.

Por outro lado, os avanços recentes da neurociência comprovam que o cérebro se assemelha a uma máquina eletroquímica, pois as ligações entre os neurônios são efetuadas a partir de neurotransmissores, mensageiros e receptores, que atuam a partir de sua estrutura química (Damásio, 1996). Assim, parece que as idéias de Prigogine se tornam pertinentes para estudos envolvendo a mente humana.

Para Prigogine (1997, p. 143),

no contexto novo da física dos processos irreversíveis, os resultados da biologia têm, evidentemente, uma significação e implicações muito diferentes. Claro que as únicas leis macroscópicas universais são, de fato, as que descrevem a evolução para a ordem, para os estados de equilíbrio ou estacionários próximos deles; mas essas leis físicas não constituem o contexto em relação ao qual o ser vivo deve definir-se: não porque é vivo, mas porque, fisicamente, não preenchem as condições de aplicações dessas leis, as condições sob as quais elas são pertinentes. O ser vivo funciona longe do equilíbrio (...) num domínio onde os processos produtores de entropia, os processos que dissipam energia, desempenham um papel construtivo, são fonte de ordem.

Estruturas dissipativas são sistemas dissipadores de matéria e de energia que podem, no curso do tempo, não só instaurar desordem, mas também a organização. Tal denominação

traduz a associação entre a idéia de ordem e a de desperdício, tendo sido escolhida de propósito para exprimir o fato fundamental novo: a dissipação de energia e de matéria - geralmente associada às idéias de perda de rendimento e de evolução para a desordem torna-se, longe do equilíbrio, fonte de ordem. (PRIGOGINE, 1997, p. 112).

Ao considerar que o acontecimento de uma reação química em si constitui um tipo de processo, caracterizado por um "início" e um "fim", que não se submete às teorias da física reversível, o mesmo autor afirma que as estruturas dissipativas podem ser denominadas processos auto-organizativos. 
Mas, por que vincular a semiose na mente humana aos processos autoorganizativos? Primeiramente por que as investigações de Peirce, que se mencionou, tratam de substâncias químicas. Nas suas palavras:

a classe de substâncias químicas que tem as moléculas mais complicadas são aquelas dos protoplasmas. Esta complexidade química é, na minha opinião, suficiente para dar conta das propriedades extraordinárias destas substâncias, pois elas se transformam em animais e plantas. Em particular, as leis de ação dos nervos são, como eu penso, indiciais para as características químicas dos protoplasmas, substâncias das quais as células nervosas são compostas. (CP 6.278)

Em segundo lugar, porque para Prigogine (1996, p. 67-8),

no equilíbrio e perto do equilíbrio, as leis da natureza são universais, longe do equilíbrio elas se tornam específicas, dependem do tipo de processos irreversíveis. Esta observação é conforme a variedade dos componentes da matéria que observamos ao nosso redor. Longe do equilíbrio, a matéria adquire novas propriedades em que as flutuações, as instabilidades desempenham um papel essencial: a matéria torna-se mais ativa.

Ainda sobre as possíveis explicações para a auto-organização, Prigogine (ibid, p. 71) diz que:

correlações de longo alcance aparecem em condições de nãoequilíbrio, correlações que não existiam no equilíbrio. Num tom metafórico, pode-se dizer que no equilíbrio a matéria é cega, ao passo que longe do equilíbrio ela começa a ver. E esta nova propriedade, esta sensibilidade da matéria a si mesma e a seu ambiente, está ligada à dissipação associada aos processos irreversíveis.

Segundo Prigogine (ibid), há algo a mais na matéria - ele menciona cegueira, que ocorre quando a matéria está em equilíbrio, e visão, em momentos distantes do equilíbrio, como especificidades da matéria. Seriam leis se atualizando ou signos em ação? Conjetura-se que tal idéia converge para um dos princípios sinequistas, o que admite a existência de leis permeando a mente e a matéria.

A seguir, explica-se o movimento dos signos/interpretantes na mente humana, considerando-se que a lei que se atualiza quando a mente se atualiza no cérebro/sistema nervoso/corpo do ser humano, é a tendência a generalizar ou a constituir leis.

\section{O movimento dos signos/interpretantes}


O signo representa, ou seja, está no lugar de algo - o objeto -, e por isso, por não ser ele mesmo o objeto, gera outro signo, o interpretante. A semiose, ou ação do signo, corresponde ao movimento da tríade signo/objeto/interpretante que não se interrompe, a não ser por necessidades práticas. O interpretante, por sua vez gera um outro signo, que gera outro...e assim sucessivamente.

A significação do signo, de acordo com Peirce, é o interpretante, ou seja, ele é o efeito do signo. Os interpretantes são classificados em imediato, dinâmico e final, o que não implica que os eles sejam entendidos como três coisas separadas. Quanto ao interpretante imediato, ele consiste na "qualidade de impressão que um signo está apto a produzir, não diz respeito a qualquer reação do fato" (CP 8.315). Assim, o interpretante imediato é o potencial interpretativo do signo.

O interpretante dinâmico, para Santaella (1995, p. 102),

é o interpretante produzido, concretização singular e particular, atualizações mais ou menos adequadas da interpretabilidade do signo rumo ao limite abstrato e ideal para o qual - mais cedo ou mais tarde, por erros e por acertos e por caminhos que não se pode de antemão estipular - os interpretantes dinâmicos tendem.

A interpretação concreta do signo produzida pelo interpretante na mente humana é o interpretante dinâmico, que está vinculado à checagem com o real, à vivência de experiências, o que realimenta a ação do signo. No movimento dos signos/interpretantes (interpretantes gerados), na mente humana, há um deslocamento incessante de um signo/interpretante para outro. Infinitos signos/interpretantes se realizam tendendo ao interpretante final.

Assim, o início do processo de autogeração corresponde à instauração de um ponto crítico, ou seja, um ponto de instabilidade a partir do qual caminhos bifurcantes ou multiramificados emergem, conforme o diagrama (figura 1). Tal ponto de instabilidade desencadeia um movimento aparentemente errático, desordenado e que pode instaurar o caos. À medida que signos/interpretados são gerados há novos embates com o real, ou seja, há checagens destes com o real, o que permeia o processo com novas realizações de qualidades de sentimento, via interpretante imediato. Deste modo, o sentir e o agir dão corpo ao movimento.

São infinitas as possibilidades do caminhar dos signos/interpretantes, logo, esse caminhar é imprevisível. No entanto, por mais diferenciados que eles sejam, há 
sempre a tendência para convergir para o interpretante final, que é da natureza de uma lei. O movimento é inicialmente caótico, o que torna as coisas inteligíveis, ou seja, não há pensamento. Mas o movimento pode se organizar e, assim, as coisas se tornam inteligíveis, ou seja, os pensamentos ganham corpo. À medida que os signos/interpretantes tendem ao interpretante final, se aproximam deste, aumenta o grau de inteligibilidade. Tal movimento se constitui como um processo autoorganizativo.

O diagrama (figura 1) exibe o movimento do caos para a organização. No entanto, simultaneamente, ocorrem movimentos da organização para o caos e depois para a organização.

O movimento dos signos/interpretantes...o pensamento

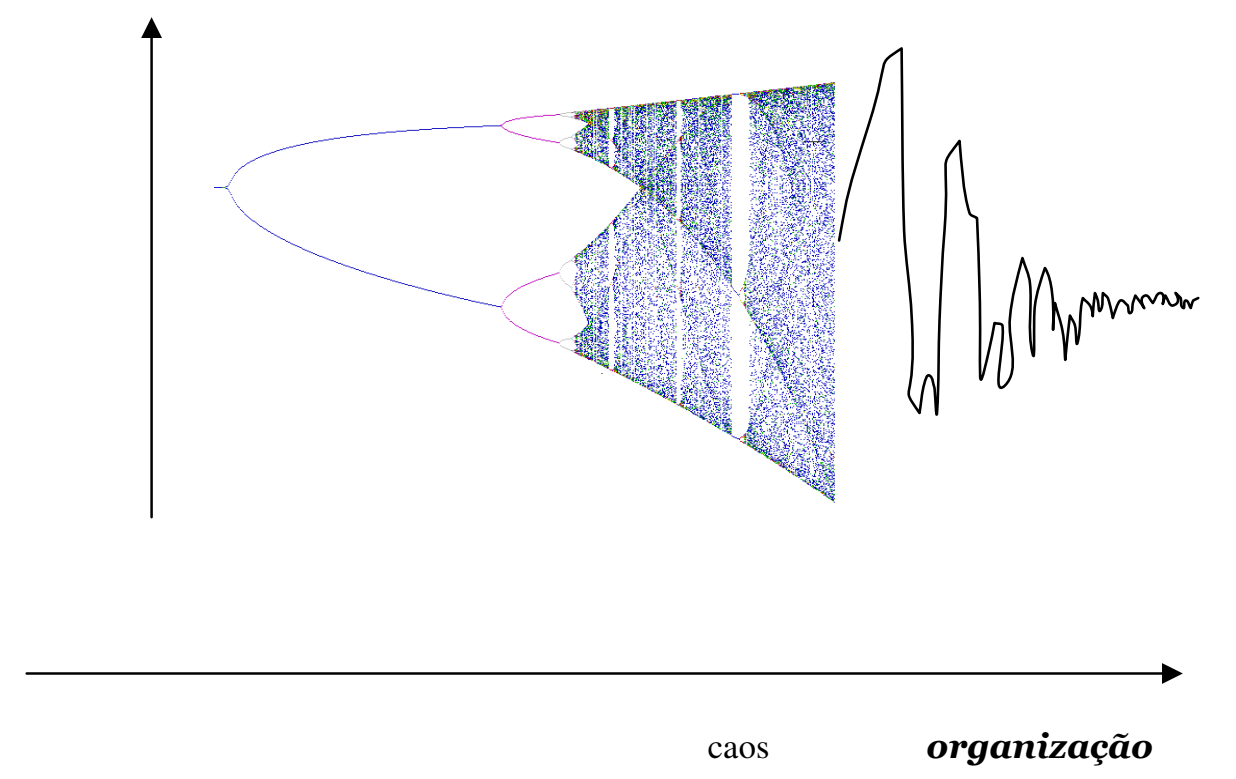

figura 1

Tal movimento, como já se mencionou, envolve a realização de uma lei. A realização da lei se percebe no tempo e por meio de mecanismos. Para explicar isto, Peirce busca a matemática. Ele argumenta que os conceitos altamente abstratos desenvolvidos na matemática são expressos por meio de regras. 
Mas processos auto-organizativos, que sejam de natureza biológica, neurológica, psicológica ou social são governados, inicialmente, pela interação dinâmica de seus componentes e, em seguida, desenvolvem arranjos fixos e exigências que os tornam mais eficientes, atingindo um grau de funcionamento maquinal.

Se o signo não altera seu potencial de gerar interpretantes, não há diferenciação no movimento dos signos/interpretantes, ou seja, os mesmos algoritmos são efetuados. Quanto maior a mecanização, menor a possibilidade de pensamentos diferenciados se constituírem e com isso menor a possibilidade de mudança de hábito. Tal movimento dissipa menos energia. Se a região do caos não se instaura, o grau de previsiblidade da mente humana aumenta, ou seja, a sua capacidade de operar mecanicamente aumenta e não possibilita o emergir do novo. Não há criatividade, no entanto, há aumento de memória.

Os movimentos mecanização/plasticidade e previsibilidade/ imprevisibilidade estão presentes. A predominância de um ou outro depende da história de semioses do intérprete. O caminhar dos signos/interpretantes não depende somente da potencialidade do signo de gerá-los, pois há uma tendência no movimento dos signos/interpretantes, uma vez que para Peirce

\begin{abstract}
se as leis da natureza são resultados da evolução, esta evolução deve proceder de acordo com algum princípio; e este princípio será, em si mesmo, da natureza de uma lei. Porém, ele deve ser igual uma lei que pode evoluir ou se desenvolver por si mesma... Evidentemente ela deve ser uma tendência à generalização - uma tendência generalizadora...Contudo, a tendência generalizadora é a grande lei da mente (CP 7.515).
\end{abstract}

Para explicar o movimento dos signos/interpretantes como um processo auto-organizativo é necessário "admitir que a lei primária e fundamental da ação mental consiste numa tendência à generalização” (CP 6.101). Há signos/interpretantes sendo gerados, no entanto, eles tendem a um interpretante final, a uma generalização. Na semiose, o interpretante imediato - como potência possibilita inúmeras atualizações de qualidades de sentimento, que facilitam o fluxo de signos/interpretantes e o caminhar para o interpretante final.

A capacidade de ver da matéria, mencionada por Prigogine, implica no processo auto-organizativo e poderia ser interpretada como a ação de signos. E 
esse movimento, guiado por uma tendência generalizadora, culminaria - em termos químicos - numa outra estrutura química organizada.

Por outro lado, onde há semiose, há consciência, pois segundo Peirce os interpretantes envolvem modificações na consciência (CP 5.485) e a mente humana mantém integrados, três categorias da consciência.

A primeira, sentimento, a consciência que pode ser incluída em um instante de tempo, consciência passiva de qualidade, sem recognição ou análises; segunda, consciência de uma interrupção no campo da consciência, sentido de resistência, de um fato externo; terceira, consciência sintética, ocorrendo no tempo, sentido de aprendizagem, pensamento (CP 1.377).

Peirce nos diz que em primeiro lugar todo tipo de consciência entra na cognição (CP 1.381). A consciência imediata ou passiva de qualidade desempenha um papel importante no emergir da consciência como um todo. Ela é tênue, mas robusta por permear as outras. A razão, como usualmente se concebe, seria o pensar que se dá sem envolver as atualizações das qualidades de sentimentos. A mente não teria atualizações diferenciadas, percorreria somente caminhos já percorridos, ou seja, a mente humana seria opaca e o seu grau de previsibilidade maior. Mas, tal razão não pode existir, pois as atualizações das qualidades de sentimento seriam finitas e não contínuas.

A qualidade de sentimento amplia a consciência sintética e com isso o grau de inteligibilidade da mente humana em relação à mente se expande e as atualizações diferenciadas podem ocorrer. Na ausência de qualidades de sentimentos permeando o processo de autogeração dos signos as atualizações da mente não se modificam. A mente humana se cristaliza, há ausência do novo. Mas algo deve permanecer. Sim, se a mente humana se atualizar sempre da mesma maneira, sempre efetuando os mesmos algoritmos, ela ganha memória.

O aumento da inteligibilidade da mente humana não prescinde de um envolvimento com qualidades. Há vestígios de qualidades de sentimento ou quantidades infinitesimais de qualidades de sentimento que se mantém de signos/interpretantes para signos/interpretantes, ou seja, é o tecido qualitativo é que mantém o movimento dos signos/interpretantes. 
A percepção da existência do tempo está associada às qualidades se sentimento. Segundo Peirce o tempo só existe se houver qualidades modificáveis continuamente.O tempo nos processos auto-organizativos emerge do caos. O tempo nasce no reino de qualidades e flui no transcorrer do processo, de modo irreversível, tal como no processo de autogeração dos signos.

Mas este movimento dos signos interpretantes constitui a atualização da mente, que é virtual. A mente humana é o produto deste processo, que pode ser descrita como uma relação virtual/atual. Nesses movimentos o ser humano pode se transformar. Viver é se constituir nestes movimentos...

A seguir, trata-se do par virtual/atual e a sua relação com a terceiridade, uma das categorias da fenomenologia peirceana.

\section{Virtual/atual e terceiridade}

Segundo Peirce (CP 8. 248), "nós não somos ignorantes dos nossos estados da mente, o que ocorre é que a mente é virtual em uma série de momentos e ela só existe num espaço de tempo - nada que dure mais do que momentos.” Logo, a mente se atualizará ao encontrar uma presença física imediata. A mente humana, como atual, existe ao encontrar o cérebro/sistema nervoso/ corpo humano.

A atualização é criação, invenção de uma forma a partir de uma configuração dinâmica de forças e finalidades. Acontece então algo mais que a dotação de realidade a um possível ou que uma escolha entre um conjunto predeterminado: uma produção de qualidades novas, (...) um verdadeiro devir que alimenta de volta o virtual (LÉVY, 1996, p. 17).

A mente humana como atualização da mente exibe o movimento mencionado, uma vez que os signos crescem e o tecido semiótico, o próprio cosmos aumenta a sua potencialidade, a sua capacidade de autogeração.

Mente e mente humana são dois modos de ser diferentes, a primeira virtual e a segunda, atual. A mente humana é uma co-produção da mente com uma instância física.

Uma atualização não é, portanto, uma mera possibilidade. O possível é algo que já está constituído, embora pareça nebuloso. Ele é algo latente, potencial, que se realizará sem que nada mude em sua determinação e em sua natureza. Por exemplo, 
a execução de um programa informático tem a ver com o possível. Quando lemos um texto na tela do computador, que estava em um suporte digital - o disquete, por exemplo -, ele contém este texto em uma linguagem diferenciada e que foi traduzida pelo computador. O leitor explora algo potencial, uma vez que o entalhe digital e o programa de leitura predeterminam um conjunto de possíveis. Pode-se esgotar todas as possibilidades num intervalo de tempo finito. As imagens exibidas na tela são possíveis.

Por maior que seja a quantidade de possíveis, não há no par potencial/realização algo problemático, algo que demande criação ou invenção na interação com uma presença física imediata. $\mathrm{O}$ armazenamento em memória digital é uma potencialização e a exibição de um possível, uma realização.

Segundo Lévy (1996, p. 15),

\begin{abstract}
a palavra virtual vem do latim medieval virtualis, derivado por sua vez de virtus, força, potência. Na filosofia escolástica, é virtual o que existe em potência e não em ato. $\mathrm{O}$ virtual tende a atualizar-se, sem ter passado, no entanto, à concretização efetiva ou formal. A árvore está virtualmente presente na semente. Em termos rigorosamente filosóficos, o virtual não se opõe ao real, mas ao atual: virtualidade e atualidade são apenas duas maneiras de ser diferentes.
\end{abstract}

$\mathrm{Na}$ atualização da mente - quando dos signos em ação no cérebro/sistema nervoso/corpo - há uma co-produção, no sentido de que o potencial dos signos, a experiência colateral do ser humano ou sua história de semioses interferem no movimento dos signos/interpretantes. Os pensamentos co-produzidos são novos, diferenciados. A atualização e a virtualização são da ordem da criação, do devir.

Quanto às atualizações da mente, além de infinitude ela envolve continuidade, pois uma atualização não se dá sem vínculos com outras. Não são simplesmente infinitas atualizações, mas um modo de ser que se desloca do virtual para o atual incessantemente e com conexões e infinitamente. Quando de atualizações não há diminuição da potência, mas modificações desta.

Mas como entender o par virtual/atual considerando as categorias fenomenológicas de Peirce? Em 1885, Peirce publicou um estudo denominado: "Um, dois, três: categorias fundamentais do pensamento e da natureza”, onde as categorias retornam, uma vez que em 1867, publicou o artigo denominado: Sobre uma nova lista 
de categorias, ampliadas à natureza. Isto porque suas investigações empíricas se prolongaram por este período e ele constatou a presença delas em diversas áreas do conhecimento como, por exemplo, a psicologia, a metafísica, a fisiologia, a física.

Há três modos pelos quais se constitui a nossa experiência, a saber: por meio da qualidade (relação monádica), da alteridade (relação diádica) e da mediação (relação triádica) e tais modos de ser constituem as categorias denominadas: primeiridade, segundidade e terceiridade, respectivamente, para Peirce (CP 1.346347).

Como primeiridade se tem um primeiro modo de ser dado pelas qualidades do fenômeno. É algo do fenômeno que não reage, que se apresenta como um objeto que não resiste. As qualidades da cor, do som, do odor, do prazer estão presentes em fenômenos completos em si mesmos e se constituem em livres possibilidades de experiência. Quando somos tomados por uma qualidade de sentimento, não há confronto e não há tempo. Não há cognição. Na realidade, a qualidade de sentimento aparece como diversidade.

Outro modo de ser do fenômeno é o da alteridade, o lado da contrariedade, da resistência. É algo que se opõe à vontade, à expectativa.

Estamos continuamente colidindo com o fato duro. Esperávamos uma coisa ou passivamente tomávamo-la por admissível e tínhamos sua imagem em nossas mentes, mas a experiência força esta idéia ao chão e nos compele a pensar muito diferentemente (CP 1.324). É ação mútua entre duas coisas sem considerar qualquer tipo de terceiro ou meio e, em particular, sem considerar qualquer lei de ação (CP 1.322).

Este modo de ser objetual é característica da segundidade. Por outro lado, a terceiridade, outro modo de ser, não se reduz às qualidades ou aos embates da segundidade. É a idéia daquilo que é tal qual é por ser um Terceiro ou Meio entre um Segundo e seu Primeiro (CP 5.66). Terceiridade é, portanto, sinônimo de mediação. No pensamento "configura-se a experiência da mediação entre um primeiro e um segundo"(IBRI, 1992, p.19).

"Mente é pensamento, e pensamento é Terceiridade, e Terceiridade é ubíqua. A mente humana é somente uma manifestação da mente, talvez a mais 
elevada porque ela tem a mais alta capacidade de autocontrole, mas não é única”. (POTTER, 1967, p.30). Assim, a mente opera por meio de signos.

Terceiridade é mediação entre puras possibilidades (Primeiridade) e fatos ou atualizações (Segundidade). Sobre leis da natureza, Peirce nos diz que "onde é mais uma mera idéia não realizada - e é da natureza de uma idéia - seria um puro primeiro. O caso para os quais se aplica - são segundos" (CP 1.342).Considerando que "geral é aquilo que naturalmente é apto a ser predicado de muitos" (CP 5.151), definição aristotélica adotada por Peirce, concluímos que a lei é um geral. De fato, pois ela se aplicará ou se atualizará, isto é, será predicado de muitos. Logo, generalidade, lei e mediação estão vinculadas.

Assim, sendo mente - Terceiridade -, como é característico deste modo de ser, ele traz consigo as atualizações (mentes humanas, por exemplo). Peirce utilizou virtual como sinônimo de potencial, toma a mente como virtual e diz da sua existência por alguns momentos, logo, conclui-se que ele se refere às atualizações da mente.

\section{Considerações finais}

Seria possível instaurar instantes de caos na mente humana? A efervescência de qualidades de sentimento - o caos -, pode ser construído ou realimentado. Para isto se fazem necessários signos com potenciais diferenciados - ou um cenário de intérpretes diversificados -, para que, de algum modo, se desencadeie o movimento dos signos/interpretantes.

As qualidades de sentimento desempenham um papel vital no movimento dos signos/interpretantes. Mas qual meio possibilita as atualizações das qualidades de sentimento? O que propicia o envolvimento com a arte? De fato, a arte desempenha um papel importante, o de nos tornar mais suscetíveis aos processos de significação. Mas não só o envolvimento com a arte ou com os seus produtos podem contribuir para a instauração da região do caos na mente humana. Os ricos processos de significação, que pode se dar envolvendo as mais diversas áreas do conhecimento, possibilitam atualizações de qualidades de sentimento. 


\section{Referências bibliográficas}

DAMÁSIO, A. R. O erro de Descartes: emoção, razão e o cérebro humano; tradução portuguesa: Dora Vicente e Georgina Segurado. São Paulo: Companhia das Letras, 1996.

DESCARTES, R. Coleção Os Pensadores; tradução de J. Guinsburg e Bento Prado Júnior. Vol.XV, São Paulo: Abril Cultural, 1973.

IBRI, Ivo Assad. Kósmos Nöetós: a arquitetura metafísica de Charles S. Peirce. São Paulo: Perspectiva, 1992.

LÉVY, Pierre.O que é o virtual?; tradução: Paulo Neves. São Paulo: Ed.34, 1996.

PEIRCE, C. S. Collected Papers. Cambridge, Massachusetts, Harvard University Press.

. Antologia Filosófica. Tradução: António Machuco Rosa. Imprensa Nacional - Casa da Moeda, 1998.

POTTER, Vincent G..Charles S. Peirce on Norms \& Ideals. The University of Massachusetts Press, 1967.

PRIGOGINE, I. e STENGERS, I.. A Nova Aliança: Metamorfose da Ciência; tradução: Miguel Faria e Maria Joaquina Machado Trincheira. Brasília: Editora Universidade de Brasília, 1997.

PRIGOGINE, I.. O fim das certezas: tempo, caos e as leis da natureza; tradução: Roberto Leal Ferreira. São Paulo: Editora da Universidade Estadual Paulista.Portugal: Edições 70, 1996.

SANTAELLA, L.. Teoria Geral dos Signos. Semiose e Autogeração. São Paulo: Ática, 1995. 